\title{
Fibronectin I promotes migration and invasion of papillary thyroid cancer and predicts papillary thyroid cancer lymph node metastasis
}

This article was published in the following Dove Press journal:

OncoTargets and Therapy

22 March 2017

Number of times this article has been viewed

\author{
Shujun Xia' \\ Chuandong Wang ${ }^{2}$ \\ Emily Louise Postma ${ }^{3}$ \\ Yanhua Yang' \\ Xiaofeng $\mathrm{Ni}^{\prime}$ \\ Weiwei Zhan' \\ 'Ultrasound Department, Ruilin \\ Hospital, Shanghai Jiao Tong University \\ School of Medicine, ${ }^{2}$ Key Laboratory \\ of Stem Cell Biology, Institute \\ of Health Sciences, Shanghai Jiao \\ Tong University School of Medicine \\ (SJTUSM) and Shanghai Institutes \\ for Biological Sciences (SIBS), \\ Chinese Academy of Sciences (CAS), \\ Shanghai, China; ${ }^{3}$ Department of \\ Surgery, University Medical Center \\ Utrecht, Utrecht, the Netherlands
}

Correspondence: Weiwei Zhan Ultrasound Department, Ruilin Hospital, Shanghai Jiao Tong University School of Medicine, 197 Rui Jin Er Road, Huang Pu, Shanghai 200025, China

Tel +86 I80 1943 1399

Email shanghairuijinus@।63.com

\begin{abstract}
Lymph node metastasis (LNM) is common in papillary thyroid cancer (PTC), and is an indicator of recurrence. The detailed molecular mechanism of LNM in PTC has not been well described. This study aimed to investigate the role of fibronectin 1 in PTC LNM and its clinical relevance. The expression of fibronectin 1 was confirmed in PTC tissues and cell lines. A correlation analysis was conducted and a receiver-operating characteristic curve obtained. The effect of fibronectin 1 on the proliferation of PTC cell lines was performed using a colonyformation assay and Cell Counting Kit 8. Cell-cycle analysis was performed with a flowcytometry assay. Migration and invasion ability were evaluated by transwell and wound-healing assays. Fibronectin 1 was overexpressed in metastasized PTC. Overexpressed fibronectin 1 was positively correlated with PTC LNM. Receiver-operating characteristic analysis showed that the diagnostic accuracy of fibronectin 1 was $81.1 \%$, with sensitivity of $80 \%$ and specificity of $82 \%$. Overexpression of fibronectin 1 promoted proliferation, migration, and invasion in PTC. Fibronectin 1 plays a critical role in PTC metastasis by modulating the proliferation, migration, and invasion ability of PTC cells, and it is a valuable diagnostic biomarker for predicting PTC LNM.
\end{abstract}

Keywords: fibronectin 1, papillary thyroid cancer, lymph node metastasis, diagnostic biomarker

\section{Introduction}

The incidence of thyroid cancer (TC) has been increasing rapidly in the past decade. Papillary TC (PTC) is the most common type of TC, and has a high probability of spreading to regional lymph nodes. ${ }^{1-4}$ Lymph node metastasis (LNM) is frequently detected in PTC at a rate of $30 \%-90 \%,{ }^{5}$ with both clinical and occult neck LN involvement. The presence of LNM does not affect survival, but it is an indicator for PTC recurrence. ${ }^{6,7}$

The choice of surgical management for PTC largely depends on whether there is cervical LN involvement at presentation, because a secondary operation for recurrent LN disease has a high risk for complications, such as recurrent laryngeal nerve injury and hypoparathyroidism. However, surgical decisions can only be appropriately made based on clinically evident LNM, and the identification of occult LNM remains difficult. Ultrasound detection at present is the best and simplest way to examine the cervical LN status of PTC preoperatively. However, ultrasound sensitivity in diagnosing cervical LNM is extremely low, with a value of $10.5 \%$ in the central compartment and $27.2 \%$ in the lateral compartment, according to previous reports. ${ }^{8,9}$ Therefore, the approach for evaluating the cervical LN status needs to be optimized. 
Improving our understanding of underlying molecular alterations in TC with LNM would be of great value for identifying cervical LNM in PTC. Fibronectin 1, a fundamental component of the extracellular matrix, is one of the biomarkers of epithelial-mesenchymal transition (EMT), which is an essential step in cancer progression. Serum fibronectin could be a promising biomarker for detecting breast cancer at an early stage. ${ }^{10}$ Another recent study indicated that fibronectin 1 was upregulated in aggressive TC. ${ }^{11}$ However, the biological function of fibronectin 1 in PTC has never been reported, and the clinical significance of fibronectin 1 in LNM of papillary TC is still unclear. ${ }^{12,13}$

In this study, we investigated the expression level of fibronectin 1 in PTC patients with or without LNM. The patients' clinicopathological characteristics were collected, and a correlation study was performed. The study also analyzed the diagnostic value of fibronectin 1 in identifying PTC LNM. In addition, the role of fibronectin 1 was evaluated by gain- and loss-of-function studies in the appropriate PTC cell lines.

\section{Materials and methods}

\section{Sample collection and ethics statement}

Tissue samples were collected from 90 PTC patients who had undergone thyroidectomy with lymphadenectomy in our hospital from August 2014 to December 2015. All cases were pathologically diagnosed as PTC with or without metastasis. The tissues were flash-frozen in liquid nitrogen and kept at $-80^{\circ} \mathrm{C}$. Patient clinicopathological characteristics were collected for the database. Written informed consent was obtained from all patients. The study was approved by the research ethics committee of Ruijin Hospital.

\section{Total RNA extraction and qRT-PCR detection}

Total RNA was extracted from the frozen tissues and cell lines using Trizol reagent (Thermo Fisher Scientific, Waltham, MA, USA) according to the manufacturer's protocol. Fibronectin 1-expression level was evaluated in 90 PTC samples by quantitative reverse-transcription polymerase chain reaction (qRT-PCR): $1 \mu \mathrm{g}$ of total RNA was reverse-transcribed into first-strand complementary DNA according to the protocol of the RT kit (Takara, Kusatsu, Japan). qRT-PCR was performed using an SYBR Premix Ex Taq II Kit (Takara) according to the VIIA7 system instructions (Thermo Fisher Scientific). All amplifications were normalized by GAPDH. Data were analyzed using the comparison Ct method $\left(2^{-\Delta \Delta C t}\right)$ and expressed as fold change compared to the control group. Each sample was analyzed in triplicate. The primer sequences used in this study were as follows: fibronectin 1, 5'-GACGCATCACTTGCACTTCT-3' (forward) and 5'-GATGCACTGGAGCAGGTTTC-3' (reverse); GAPDH, 5'-AAGGTGAAGGTCGGAGT CAAC-3' (forward) and 5'-GGGGTCATTGATGGCAACAA TA-3' (reverse).

\section{Cell culture}

The human PTC cell lines TPC1 and K1 were kind gifts from the Key Laboratory for Endocrine and Metabolic Diseases of the Chinese Health Ministry, Department of Endocrinology and Metabolism, Ruijin Hospital (Shanghai, China). K1 and TPC1 are both well-differentiated PTC cell lines; K1 retains the property of metastasis, while TPC1 does not. ${ }^{14}$ TPC1 was cultured in Roswell Park Memorial Institute 1640 HEPES medium supplemented with $10 \%$ fetal bovine serum (FBS), $100 \mathrm{U} / \mathrm{mL}$ penicillin, and $100 \mu \mathrm{g} / \mathrm{mL}$ streptomycin, and K1 was cultured in Dulbecco's Modified Eagle's Medium (all Thermo Fisher Scientific), MCDB (Sigma-Aldrich, St Louis, MO, USA), F12 (2:1:1) supplemented with 10\% FBS, and $100 \mathrm{U} / \mathrm{mL}$ penicillin with $100 \mu \mathrm{g} / \mathrm{mL}$ streptomycin. The two cell lines were incubated at $37^{\circ} \mathrm{C}$ in a $5 \% \mathrm{CO}_{2}$ humidified atmosphere.

\section{Cell-line transfection}

For the overexpression experiment, fibronectin 1-overexpression lentiviral was purchased from Hanbio Biotech Co Ltd (Shanghai, China); fibronectin 1 complementary DNA was ligated into pLVX-IRES-Puro (Takara) to construct the fibronectin 1-overexpression plasmid. pLVX-IRESpuro and pRUF-IRES-Puro-fibronectin 1 constructs were transfected into the HEK293T viral packaging cell line with the psPAX2 and pMD2.G (Thermo Fisher Scientific) plasmids. At 48 hours after transfection, the viral supernatant was collected and used for TPC1 infection. For the knockdown experiment, K1 cells were transfected with $100 \mathrm{nM}$ fibronectin 1-specific short hairpin RNA (shRNA) (TL304489; OriGene, Rockville, MD, USA) or ineffective control shRNA (OriGene) using Lipofectamine 2000 (Thermo Fisher Scientific) according to the manufacturer's instructions. Messenger RNA (mRNA)- and protein-expression levels of fibronectin 1 were detected by qRT-PCR and Western blot analysis, respectively.

\section{Western blot analysis}

At 48 hours after transfection, protein lysate was acquired from collected cells with radioimmunoprecipitation assay, and the supernatant was collected after a 30-minute reaction on ice and 15 -minute centrifugation at $13,000 \mathrm{rpm}$. The protein 
concentration was determined using a BCA protein-assay kit (Thermo Fisher Scientific). An equal amount of $10 \mu \mathrm{g}$ of protein from each condition was subjected to electrophoresis on $8 \%$ sodium dodecyl sulfate polyacrylamide-gel electrophoresis and subsequently transferred to polyvinylidene difluoride membrane, which was then blocked with 5\% bovine serum albumin in Tris-buffered saline containing $0.1 \%$ Tween 20 at room temperature for 1 hour. Incubation was conducted with primary antibodies at $4^{\circ} \mathrm{C}$ overnight, which was followed by secondary antibodies at room temperature for 1 hour. Membranes were washed three times with washing buffer (phosphate-buffered saline containing $0.1 \%$ Tween) for 10 minutes after each incubation. Images were then captured using an Odyssey infrared fluorescence scanner (LI-Cor, Lincoln, NE, USA). We used primary antibodies recognizing human fibronectin 1 mouse monoclonal antibodies (1:1,000; R\&D systems, Minneapolis, MN, USA), GAPDH, and rabbit monoclonal antibodies (1:2,000; Cell Signaling Technology, Danvers, MA, USA).

\section{CCK-8 analysis}

At 48 hours after transfection, TPC1 and $\mathrm{K} 1$ cells were seeded into 96-well plates at a density of $10^{4}$ cells/well. Cell viability was evaluated with the Cell Counting Kit (CCK)-8 (Dojindo Molecular Technologies, Mashiki, Japan) at 0, 12, 24, 36, 48, and 72 hours. Absorbance was determined with an Infinite M200 plate reader (Tecan, Männedorf, Switzerland) at $450 \mathrm{~nm}$.

\section{Colony-formation assay}

At 48 hours after transfection, TPC1 and K1 cells were seeded in six-well plates at a density of 500 cells/well and cultured at $37^{\circ} \mathrm{C}$ in a $5 \% \mathrm{CO}_{2}$ humidified atmosphere. The culture medium was changed every other day. After 7 days in culture, the medium was removed and cells washed twice with phosphate-buffered saline. Then, the cells were fixed with methanol for 20 minutes and stained with $1 \%$ crystal violet for 30 minutes at room temperature, washed again, and photographed.

\section{Flow-cytometry assay}

After 48 hours of transfection, TPC1 and K1 cells were collected for cell-cycle analysis. Cells were fixed in $75 \%$ ethanol overnight at $4{ }^{\circ} \mathrm{C}$ and then stained with a cell-cycle analysis kit (Beyotime Biotechnology, Haimen, China) according to the manufacturer's instructions. The cells were analyzed by Gallios flow cytometry (Beckman Coulter, Brea, CA, USA) to quantify the cell cycle. All experiments were performed independently in triplicate.

\section{Wound-healing assay}

Cells were plated in each well of six-well plates and incubated to achieve $100 \%$ confluence. Then, a scratch was performed with a pipette tip. Fresh serum-free medium was changed. The wound-closing process was observed for 24 hours, and images were collected using microscopy (Carl Zeiss Meditec AG, Jena, Germany).

\section{Transwell assay}

Transwell chambers with $8 \mu \mathrm{m}$ pores (Costar; Corning, New York, NY, USA) were used to perform the migration and invasion assays. Matrigel (BD Biosciences, Franklin Lakes, NJ, USA) was coated on the top side of the insert membrane in the invasion assay. The upper chamber was treated with $200 \mu \mathrm{L}$ of serum-free medium and seeded with $10^{4}$ cells, and the lower chamber was treated with $600 \mu \mathrm{L}$ of medium with $5 \% \mathrm{FBS}$. The chambers were maintained at $37^{\circ} \mathrm{C}, 5 \% \mathrm{CO}_{2}$ for 24 hours. Afterward, the unmigrated or uninvaded cells on the top of the insert membrane were removed by cotton swabs. The inserts were then fixed in methanol for 20 minutes and stained with $1 \%$ crystal violet for 30 minutes. The migrated or invaded cells on the bottom of the membrane were investigated under a microscope and photographed. All experiments were performed in triplicate.

\section{Statistical analysis}

Statistical analysis was performed with SPSS 19.0 software (IBM, Armonk, NY, USA) and GraphPad Prism 5.0 (GraphPad Software, La Jolla, CA, USA). Categorical variables are described as proportions, and descriptive variables presented as means \pm standard deviation. Pearson's $\chi^{2}$ test was applied in the correlation analysis of fibronectin 1 and clinicopathological characteristics. Independent two-sample $t$-tests were used to compare fibronectin 1-expression levels of the two independent groups. Univariate and multivariate logistic regression analysis was performed to study the risk factors for LNM. The significant variables $(P<0.05)$ in univariate analysis were included in multivariate analysis. The sensitivity, specificity, positive predictive value, negative predictive value, and diagnostic accuracy of fibronectin 1 were assessed with a receiver-operating characteristic (ROC) curve and area under the curve (AUC). $P<0.05$ was considered indicative of a statistically significant difference.

\section{Results}

\section{Patient clinicopathological characteristics}

As shown in Table 1, a total of 90 patients were included in our study. They were classified into two groups (LNM group, $\mathrm{n}=40$; non-LNM group, $\mathrm{n}=50$ ) according to whether the 
Table I Patient characteristics

\begin{tabular}{|c|c|c|c|c|}
\hline $\begin{array}{l}\text { Clinicopathological } \\
\text { characteristics }\end{array}$ & $\begin{array}{l}\text { All patients, } \\
\text { n (\%) }\end{array}$ & $\begin{array}{l}\text { LNM } \\
(n=40)\end{array}$ & $\begin{array}{l}\text { Non-LNM } \\
(n=50)\end{array}$ & $P$-value \\
\hline Sex & & & & 0.625 \\
\hline Male & 22 (24.4\%) & II (27.5\%) & II (22\%) & \\
\hline Female & 68 (75.6\%) & 29 (72.5\%) & 39 (78\%) & \\
\hline Age & & & & 0.672 \\
\hline$<45$ years & 38 (42.2\%) & I 8 (45\%) & $20(40 \%)$ & \\
\hline$\geq 45$ years & 52 (57.8\%) & $22(55 \%)$ & $30(60 \%)$ & \\
\hline Focalization & & & & 0.15 \\
\hline Unifocal & $66(73.3 \%)$ & $26(65 \%)$ & $40(80 \%)$ & \\
\hline Multifocal & $24(26.7 \%)$ & 14 (35\%) & $10(20 \%)$ & \\
\hline Tumor & & & & 0.000 \\
\hline Tla & $59(65.6 \%)$ & I 8 (45\%) & 41 (82\%) & \\
\hline TIb & 31 (34.4\%) & $22(55 \%)$ & $9(18 \%)$ & \\
\hline Lymph node & & & & - \\
\hline No & $50(55.6 \%)$ & - & - & \\
\hline $\mathrm{Nla}$ & 26 (28.9\%) & - & - & \\
\hline NIb & 14 (I5.5\%) & - & - & \\
\hline \multicolumn{5}{|l|}{ Metastasis } \\
\hline MO & 90 (100\%) & - & - & - \\
\hline \multicolumn{5}{|l|}{ pTNM stage } \\
\hline Early (I/II) & $68(75.6 \%)$ & 18 (45\%) & $50(100 \%)$ & 0.000 \\
\hline Advanced (III/IV) & $22(24.4 \%)$ & 22 (55\%) & 0 & \\
\hline
\end{tabular}

Abbreviations: LNM, lymph node metastasis; PTNM, pathological tumor, node, metastasis. patient had LNM. The sex, age and focalization distribution in the two groups were comparable $(P>0.05)$. According to the American Joint Committee on Cancer staging system (seventh edition), the tumors were all pT1, and thus significant observations were limited to T1 tumors. No patients had distant metastasis. In the LNM group, $65 \%$ of the patients were N1a and $35 \%$ N1b. Patients with LNM were significantly more likely to be at an advanced stage (III/IV, 55\%; $P<0.05$ ).

\section{Fibronectin I is overexpressed in metastatic PTC}

Fibronectin 1 expression was analyzed in tumor tissues for 90 patients, as well as PTC cell lines (TPC1 and K1). qRTPCR results showed that the mRNA-expression level of fibronectin 1 was significantly higher in PTC patients with LNM, as well as in a $\mathrm{K} 1$ cell line that retained the property of metastasis (Figure 1A and B). Subsequently, the protein expression level of fibronectin 1 was confirmed in cell lines by Western blot analysis (Figure $1 \mathrm{C}$ and $\mathrm{D}$ ), which was consistent with the mRNA-expression level.
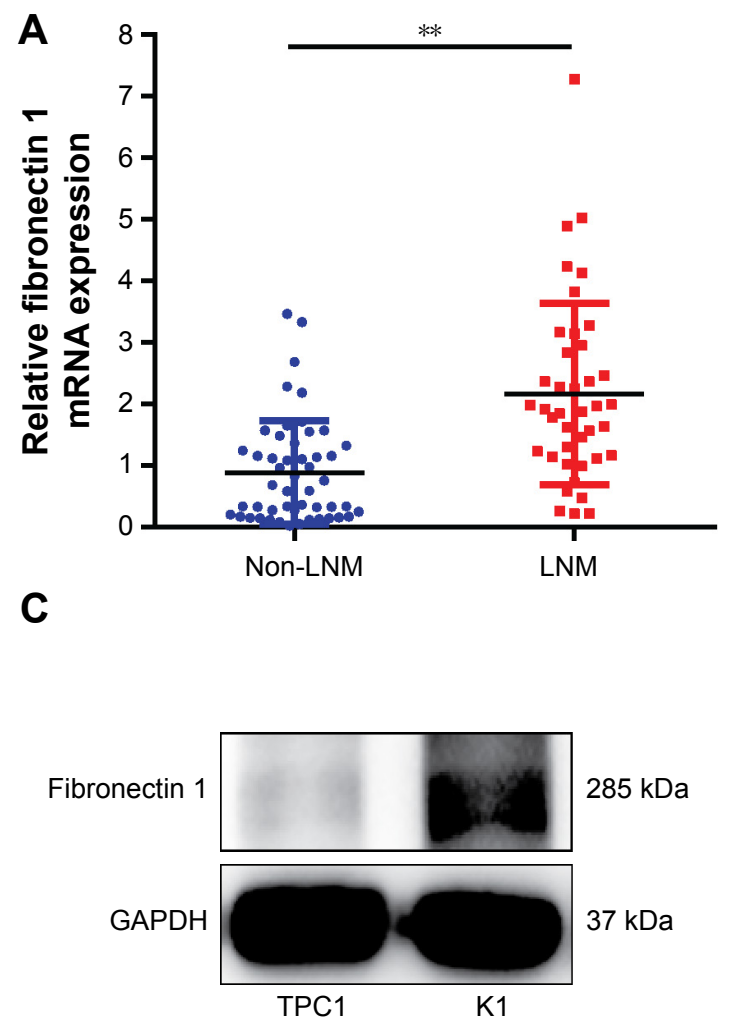
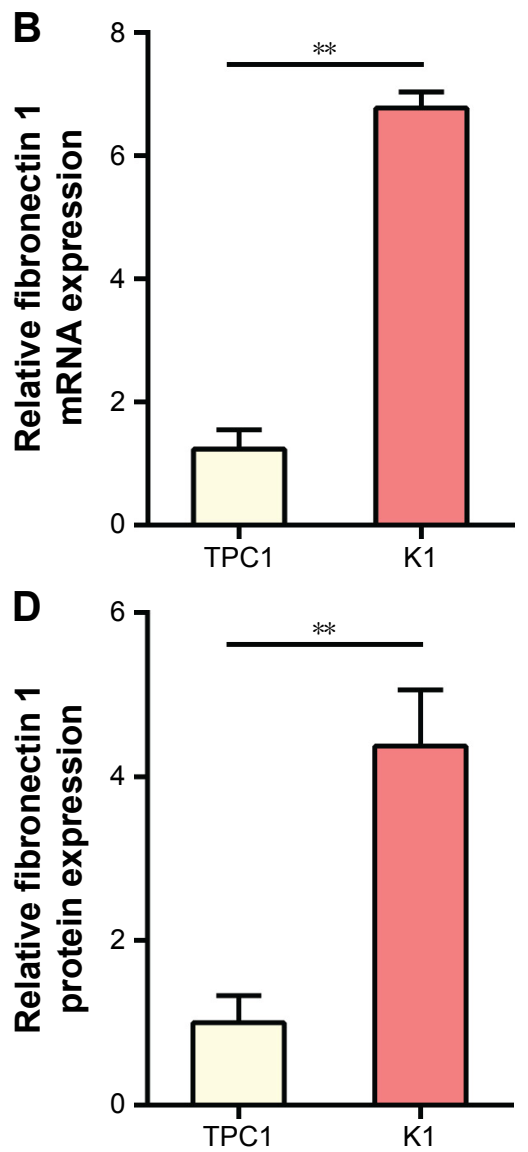

Figure I Fibronectin I is overexpressed in metastatic PTC.

Notes: **P $<0.05$. qRT-PCR analysis of the expression levels of fibronectin I in PTC tissues (unmetastasized, $n=50$; metastasized, $n=40$ ) (A) and PTC cell lines (TPCI and KI) (B). The values were normalized to GAPDH mRNA expression. Data expressed as means \pm standard deviation of three independent experiments. (C, D) Western blot analysis of fibronectin I in TPCI and KI cells. GAPDH was used as a loading control.

Abbreviations: PTC, papillary thyroid cancer; qRT-PCR, quantitative reverse-transcription polymerase chain reaction; mRNA, messenger RNA. 


\section{Fibronectin I overexpression is associated with lymph node metastasis in PTC}

Fibronectin 1 was confirmed to be overexpressed in metastatic PTC. We further analyzed the correlation of fibronectin 1 expression and clinicopathological characteristics of all patients. The relative expression of fibronectin 1 was constructed on an ROC curve. The cutoff value $(\Delta C t=4.161)$ of fibronectin 1 expression was calculated by ROC-curve analysis with SPSS software. At the cutoff point of 4.161, the AUC met the maximum, indicating the best diagnostic accuracy of fibronectin 1 differentiating PTC LNM. According to the cutoff expression level of fibronectin 1 in all PTC samples, patients were categorized into a low-expression group ( $\mathrm{n}=49$, $\Delta \mathrm{Ct}>4.161)$ and a high-expression group $(\mathrm{n}=41, \Delta \mathrm{Ct}<4.161)$. Patients with lower fibronectin 1 expression $(\Delta \mathrm{Ct}>4.161)$ were identified as unmetastasized PTC, whereas those with higher fibronectin 1 expression $(\Delta \mathrm{Ct}<4.161)$ were metastasized PTC (Table 2). As summarized in Table 3, fibronectin 1 overexpression was significantly correlated with tumor size (T1a vs T1b, $P=0.044$ ), LNM in PTC (N0 vs N1a and N1b, $P=0.000$ ), and pathological TNM (pTNM; tumor, node, metastasis) stage (I-II vs III-IV, $P=0.000$ ). There were no significant associations between fibronectin 1 expression and sex $(P=0.806)$, age $(P=1.000)$, or focalization $(P=1.000)$. Moreover, univariate and multivariate logistic regression analyses showed that fibronectin 1 overexpression was a strong independent diagnostic factor for LNM in PTC patients $(P=0.000)$ (Table 4).

\section{Fibronectin I is a potential diagnostic biomarker for differentiating lymph node metastasis in PTC}

To evaluate further the possibility of clinical application of fibronectin 1 in PTC patients, the diagnostic potential and discriminatory accuracy of fibronectin 1 was evaluated by ROC-curve analysis and corresponding AUC values. The AUC for fibronectin 1 was 0.814 (95\% confidence interval 0.723 $0.905, P<0.000$, Figure 2). The highest diagnostic value was at a cutoff point of 4.161, where the negative predictive value, positive predictive value, sensitivity, and specificity to identify PTC LNM were $83.7 \%, 78 \%, 80 \%$, and $82 \%$, respectively, with a diagnostic accuracy of $81.1 \%$ (Table 5).

Table 2 Fibronectin I evaluation and pathological results for metastatic cervical lymph nodes

\begin{tabular}{llll}
\hline Fibronectin I & \multicolumn{2}{l}{ Pathologic diagnosis } \\
\cline { 2 - 4 } & Positive nodes & Negative nodes & Total \\
\hline High expression & 32 & 9 & 41 \\
Low expression & 8 & 41 & 49 \\
Total & 40 & 50 & 90 \\
\hline
\end{tabular}

Table 3 Correlations between fibronectin I expression and clinicopathological characteristics in PTC

\begin{tabular}{|c|c|c|c|c|}
\hline $\begin{array}{l}\text { Clinicopathological } \\
\text { characteristics }\end{array}$ & $\mathbf{n}$ & $\begin{array}{l}\text { High } \\
\text { expression }\end{array}$ & $\begin{array}{l}\text { Low } \\
\text { expression }\end{array}$ & $P$-value \\
\hline Sex & & & & 0.806 \\
\hline Male & 22 & II (26.8\%) & II (22.4\%) & \\
\hline Female & 68 & 30 (73.2\%) & 38 (77.6\%) & \\
\hline Age & & & & 1.000 \\
\hline$<45$ years & 38 & 17 (4I.5\%) & 21 (42.9\%) & \\
\hline$\geq 45$ years & 52 & $24(58.5 \%)$ & $28(57.1 \%)$ & \\
\hline Focalization & & & & 1.000 \\
\hline Unifocal & 66 & 30 (73.2\%) & $36(73.5 \%)$ & \\
\hline Multifocal & 24 & II (26.8\%) & $13(26.5 \%)$ & \\
\hline Tumor & & & & 0.044 \\
\hline Tla & 59 & $22(53.7 \%)$ & 37 (75.5\%) & \\
\hline TIb & 31 & 19 (46.3\%) & $12(24.5 \%)$ & \\
\hline Lymph node & & & & 0.000 \\
\hline No & 50 & $9(22 \%)$ & $4 \mathrm{I}(83.7 \%)$ & \\
\hline $\mathrm{Nla}$ & 26 & $22(53.7 \%)$ & $4(8.2 \%)$ & \\
\hline NIb & 14 & 10 (24.4\%) & 4 (8.1\%) & \\
\hline Metastasis & & & & - \\
\hline MO & $90(100 \%)$ & - & - & \\
\hline pTNM stage & & & & 0.000 \\
\hline Early (I-II) & 68 & $23(56.1 \%)$ & 45 (91.8\%) & \\
\hline Advanced (III-IV) & 22 & I8 (43.9\%) & $4(8.2 \%)$ & \\
\hline
\end{tabular}

Abbreviations: PTC, papillary thyroid cancer; PTNM, pathological tumor, node, metastasis.

\section{Fibronectin I knockdown suppresses K I proliferation}

A loss-of-function experiment was performed on the K1 cell line. Transfection efficiency was estimated by qRT-PCR and Western blot analysis, showing that the fibronectin 1-expression level was knocked down significantly by shRNA (Figure $3 \mathrm{~A}$ and $\mathrm{B}$ ). In CCK-8 assays, the proliferation ability of $\mathrm{K} 1$ cells was examined at six time points $(0,12,24,36,48$, and 72 hours) after transfection. Cell viability was shown as a proliferation curve based on absorbance at $450 \mathrm{~nm}$. The proliferation ability of cells in the fibronectin 1 shRNA group was inhibited compared to the scrambled (Scr)-shRNA control group (Figure 3C). In addition, the impact of fibronectin 1 on cell proliferation was evaluated by the colony-formation assay. The colony-formation assay showed that there were fewer clones in the fibronectin 1 shRNA group than in the control group (Figure 3D and E). The cell-cycle analysis showed that the proportion of cells in the $G_{1}$ phase was significantly higher in the fibronectin 1 shRNA group compared to the Scr-shRNA group, whereas it was lower in the $\mathrm{S}$ and $\mathrm{G}_{2} / \mathrm{M}$ phases in the fibronectin 1 shRNA group (Figure 3F and $\mathrm{G}$ ). The results indicated that the proliferation ability of PTC cells was suppressed by fibronectin 1 downregulation. 
Table 4 Univariate and multivariate regression analysis of parameters associated with LNM

\begin{tabular}{|c|c|c|c|c|c|}
\hline \multirow[t]{2}{*}{ Parameter } & \multirow[t]{2}{*}{ Category } & \multicolumn{2}{|l|}{ Univariate analysis } & \multicolumn{2}{|c|}{ Multivariate analysis } \\
\hline & & OR $(95 \% \mathrm{Cl})$ & $P$-value & OR $(95 \% \mathrm{Cl})$ & $P$-value \\
\hline$\overline{S e x}$ & Male/female & $1.345(0.53 \mathrm{I}-3.527)$ & 0.547 & & \\
\hline Age & $\geq 45 /<45$ years & $\mathrm{I} .227(0.529-2.847)$ & 0.633 & & \\
\hline Focalization & Unifocal/multifocal & $0.464(0.18-1.2)$ & 0.113 & & \\
\hline Tumor size & TIa/TIb & $0.18(0.069-0.466)$ & 0 & $0.171(0.05-0.577)$ & 0.004 \\
\hline Stage & Advanced/early & $1.687(0.021-1.93)$ & 0.098 & & \\
\hline Fibronectin I & High/low & $1.055(1.019-1.158)$ & 0 & $1.053(1.017-1.169)$ & 0 \\
\hline
\end{tabular}

Abbreviations: LNM, lymph node metastasis; OR, odds ratio; $\mathrm{Cl}$, confidence interval.

\section{Fibronectin I knockdown inhibits migration and invasion of $\mathrm{KI}$}

A wound-healing assay showed that the distance of the scratch wound in the fibronectin 1 shRNA group was significantly larger than the Scr-shRNA control group (Figure 4A). In transwellmigration assays, the number of cells migrating through the chamber in the fibronectin 1 shRNA group was significantly lower than that in the Scr-shRNA control group (Figure 4B and D). A similar result was observed in the invasion assay (Figure 4C and E). Downregulation of fibronectin 1 inhibited the migration and invasion of PTC cells.

\section{Fibronectin I overexpression promotes TPCI proliferation}

A gain-of-function experiment was performed on the TPC1 cell line. Transfection efficiency was estimated by qRT-PCR

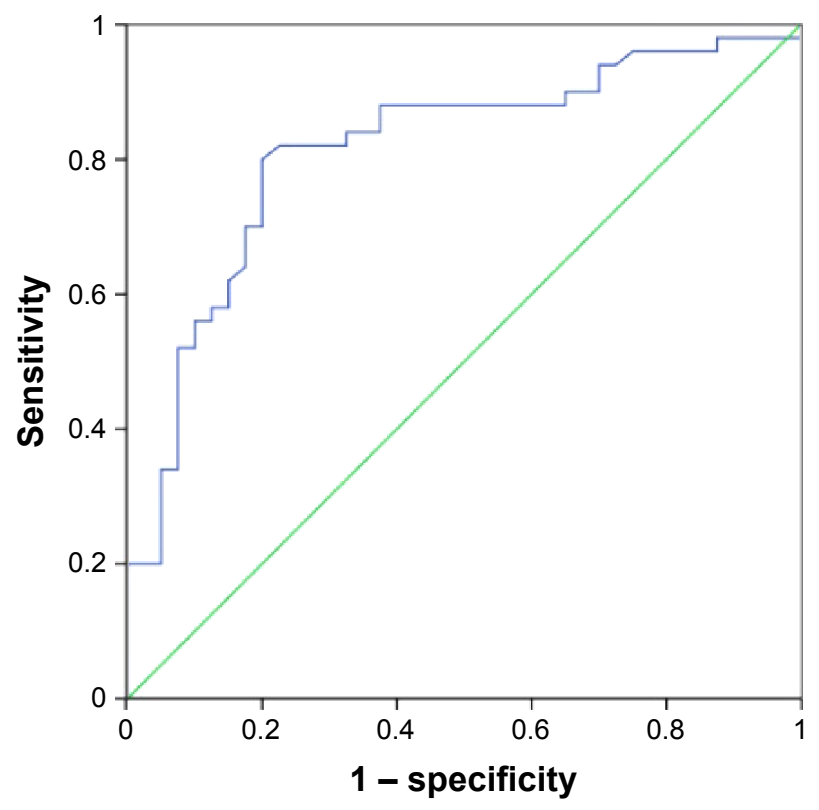

Figure 2 Potential diagnostic value of fibronectin I.

Notes: The ROC curve of fibronectin I predicted the presence of lymph node metastasis in papillary thyroid cancer in terms of sensitivity and specificity: AUC 0.814 (0.723-0.905), $P<0.000$.

Abbreviations: ROC, receiver-operating characteristic; AUC, area under the curve. and Western blot analysis, showing that fibronectin 1expression level was significantly overexpressed by lentivirus-fibronectin 1 (Figure 5A and B). CCK-8 assays examined the proliferation ability of TPC1 cells at six time points $(0,12,24,36,48$, and 72 hours) after transfection. Cell viability is shown in a proliferation curve based on absorbance at $450 \mathrm{~nm}$. Cell-proliferation ability in the lentivirus-fibronectin 1 group was higher than that in the lentivirus-vector control group (Figure 5C). Similarly, the colony-formation assay showed that the number of clones in the lentivirus-fibronectin 1 group was higher than that in the control group (Figure 5D and E). Cell-cycle analysis showed that the proportion of cells in the $\mathrm{G}_{1}$ phase was significantly lower in the lentivirus-fibronectin 1 group compared to the lentivirus-vector control group, whereas it was higher in the $\mathrm{S}$ and $\mathrm{G}_{2} / \mathrm{M}$ phases in the lentivirus-fibronectin 1 group (Figure 5F and G). The proliferation ability of PTC cells was promoted by fibronectin 1 .

\section{Fibronectin I overexpression promotes migration and invasion of TPCI}

In the wound-healing assay, the distance of the scratch wound in the lentivirus-fibronectin 1 group was significantly shorter than for the lentivirus-vector control group (Figure 6A). In a transwell-migration assay, the number of cells migrating through the chamber in the lentivirus-fibronectin 1 group was significantly higher than the control group (Figure 6B and D). A similar result was also observed in the invasion assay (Figure 6C and E). The result indicated that fibronectin 1 upregulation promoted migration and invasion of PTC cells.

\section{Discussion}

LNM occurs frequently in PTC, but there is a lack of an effective method to screen out LNM with atypical ultrasonographic characteristics or micrometastasis. The mechanism for LNM in PTC has not been clearly identified, because it is not a lethal disease. However, it is of great importance to identify the cervical node status for optimal surgical decision making 
Table 5 Performance of fibronectin I in differentiating LNM in PTC

\begin{tabular}{llllll}
\hline & Youden's index & Sensitivity & Specificity & Accuracy \\
\hline Fibronectin I & 0.6 & $80 \%$ & $82 \%$ & PPV & $83.7 \%$ \\
\hline
\end{tabular}

Abbreviations: LNM, lymph node metastasis; PTC, papillary thyroid cancer; NPV, negative predictive value; PPV, positive predictive value.

A

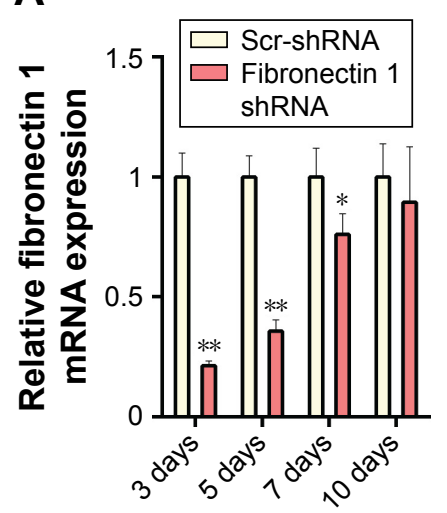

D

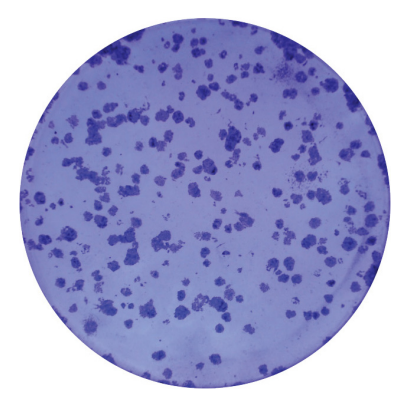

Scr-shRNA
B
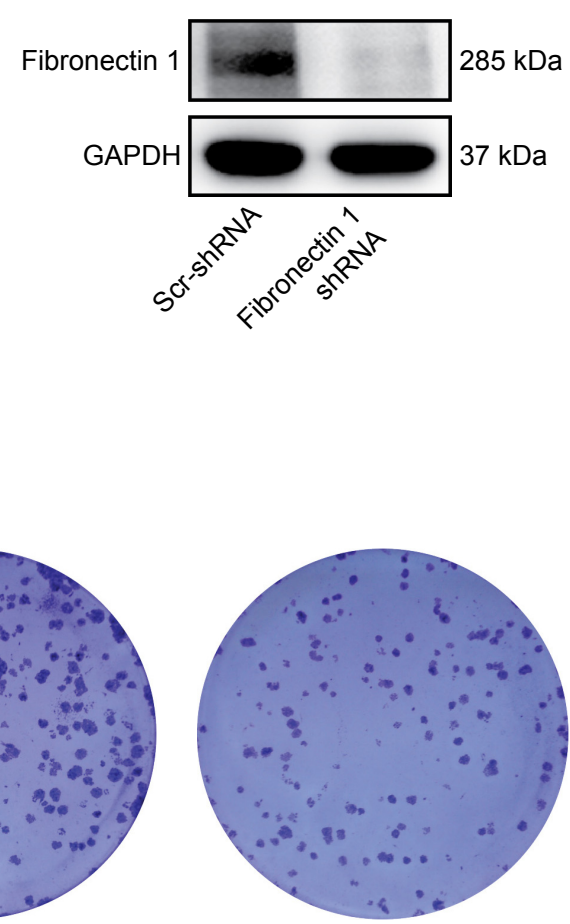

Fibronectin 1 shRNA

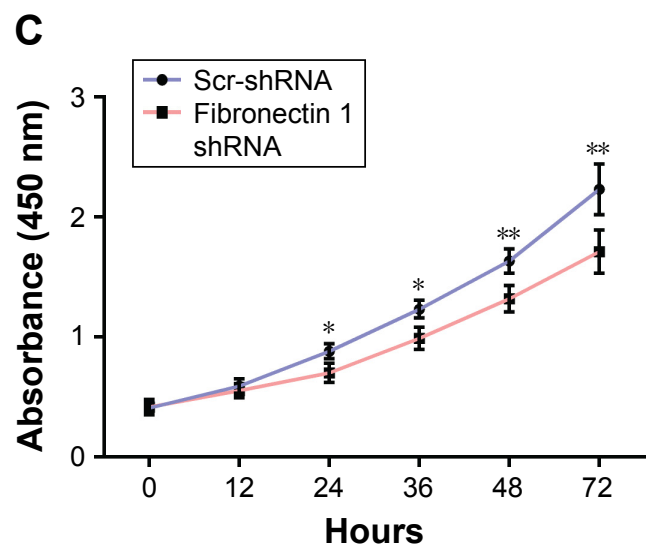

E

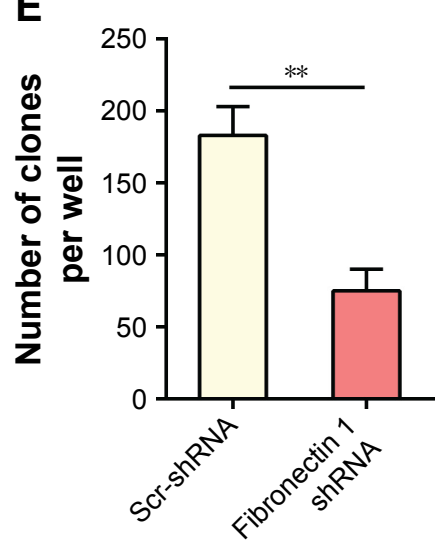

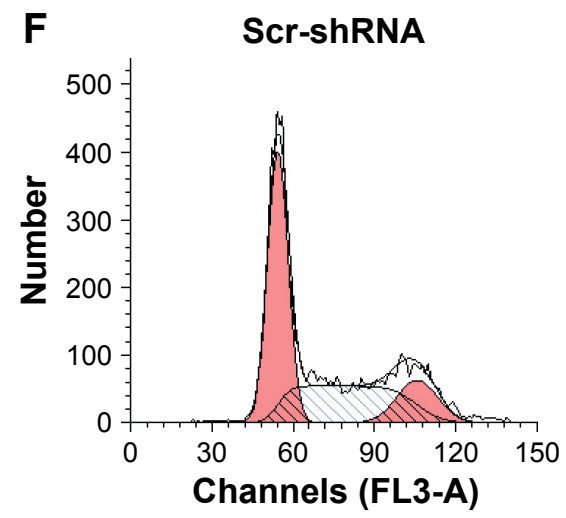
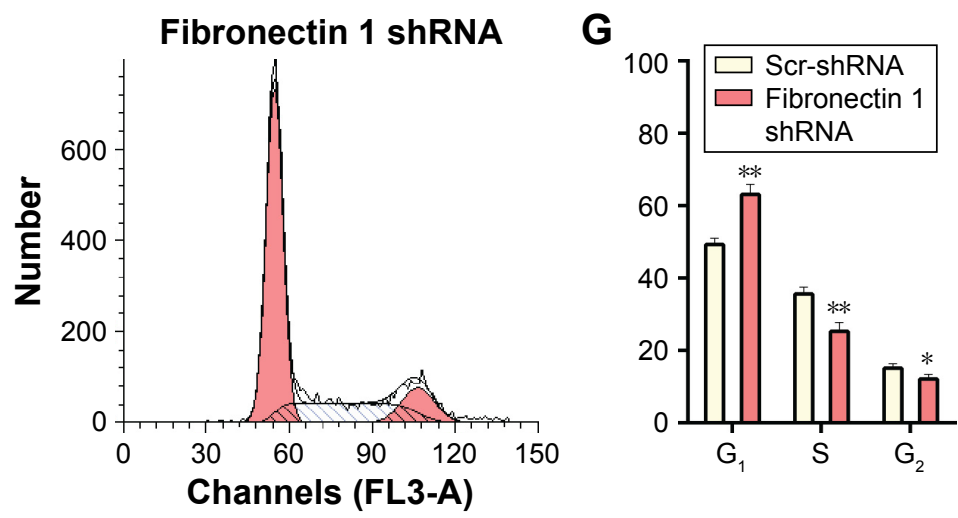

Figure 3 Fibronectin I knockdown suppresses KI proliferation.

Notes: $* P<0.05$; $* * P<0.01$. (A) qRT-PCR analysis of mRNA fibronectin I-expression levels in $\mathrm{KI}$ cells transfected with fibronectin I-specific shRNA using Lipofectamine on days 3, 5, 7, and 10. (B) Western blot analysis of fibronectin I in KI cells transfected with fibronectin I-specific shRNA. (C) CCK-8 assays were performed to determine $\mathrm{KI}$ cell proliferation after $0,12,24,36,48$, and 72 hours following transfection with fibronectin I-specific shRNA. (D) A colony-formation assay was performed to determine the proliferation of KI cells transfected with fibronectin I-specific shRNA. (E) Colony-formation assay results. (F) Flow-cytometry images of the cell cycle in KI. (G) Results quantified in the cell cycle shown as a percentage of the total cells. All experiments were independently performed in triplicate. Data presented as means \pm standard deviation.

Abbreviations: qRT-PCR, quantitative reverse-transcription polymerase chain reaction; mRNA, messenger RNA; shRNA, short hairpin RNA; Scr-shRNA, scrambled shRNA. 
in PTC. ${ }^{15}$ Reoperation as a result of recurrence is a challenge for surgeons, because of distortion of the normal tissue plane, postsurgical fibrosis, and severe adhesion. Additionally, it increases the incidence of complications, which could impact the patient's quality of life. ${ }^{16}$ A better understanding of LNM in PTC is important to improve diagnosis and therapy.
Fibronectin 1 encodes fibronectin, which presents in soluble dimeric form in the plasma and in dimeric or multimeric form at the cell surface and in the extracellular matrix. As an EMT marker, fibronectin is involved in cell adhesion and migration, including embryogenesis, ${ }^{17}$ wound healing, ${ }^{18}$ blood coagulation, ${ }^{19}$ osteogenesis, ${ }^{20}$ and
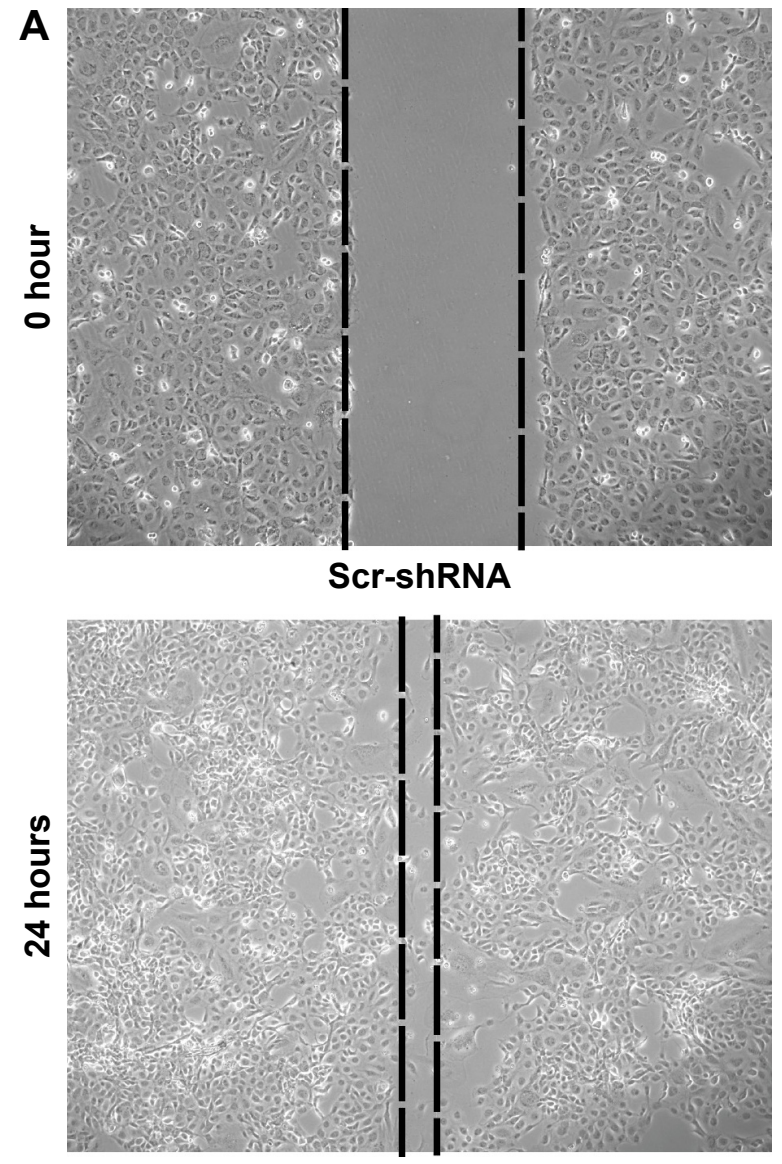

Scr-shRNA

B

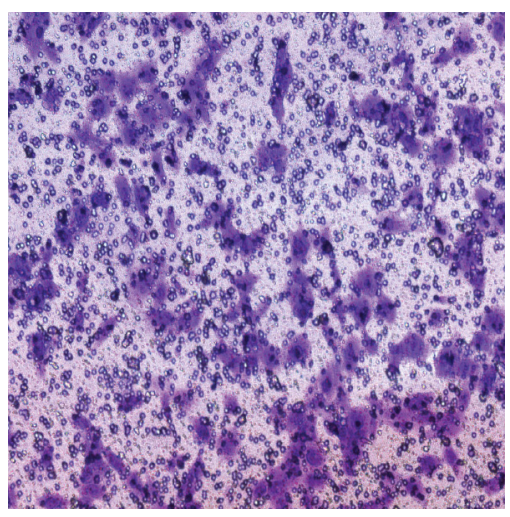

Scr-shRNA

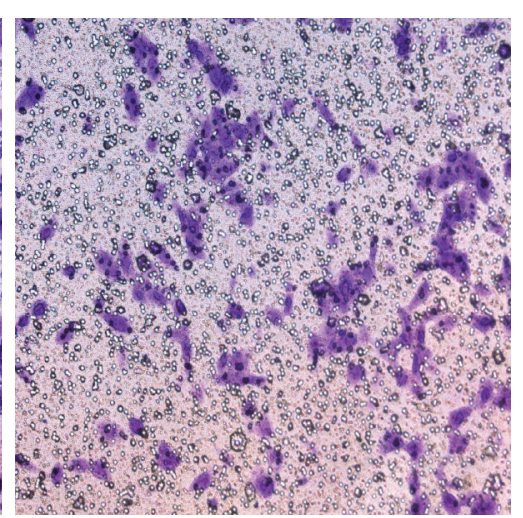

Fibronectin 1 shRNA

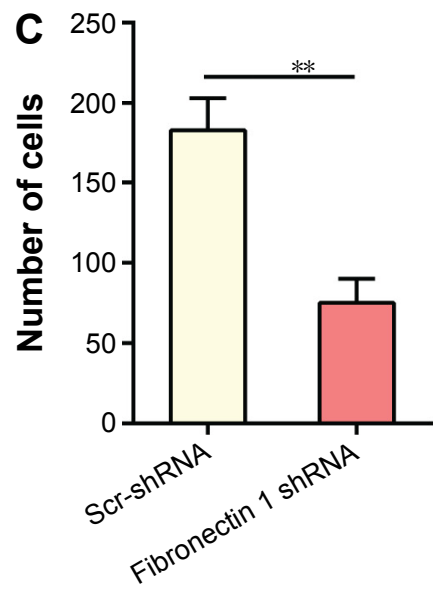

Figure 4 (Continued) 


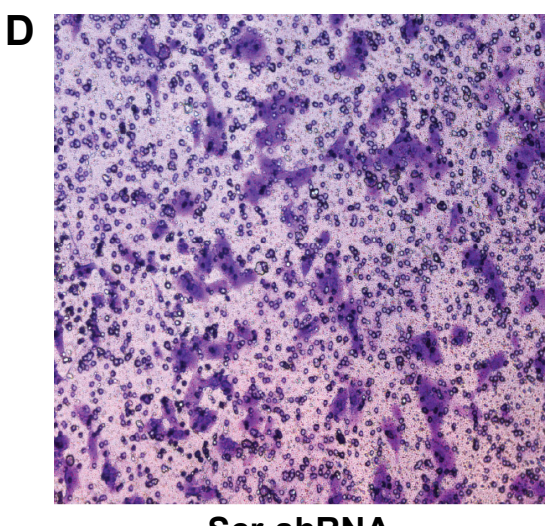

Scr-shRNA

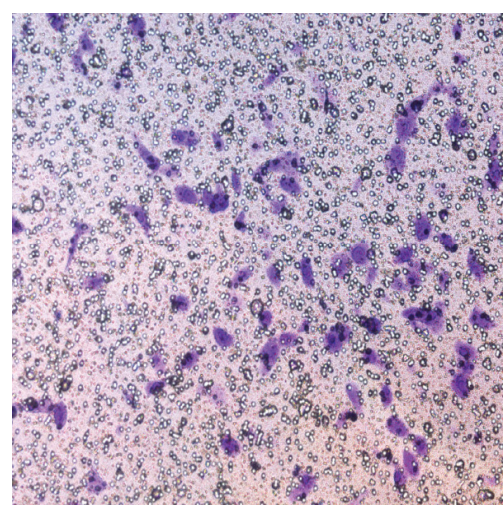

Fibronectin 1 shRNA
$\mathbf{E}$

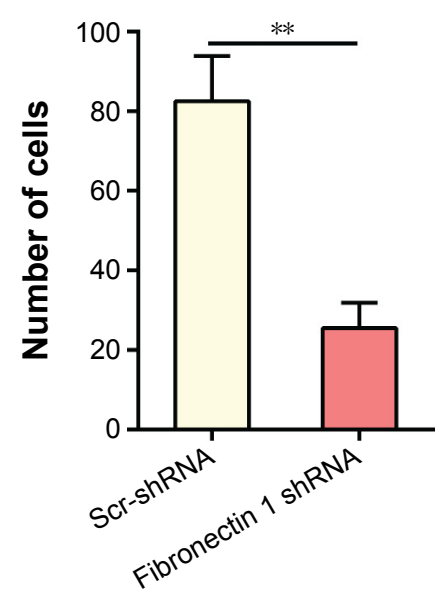

Figure 4 Fibronectin I knockdown inhibits the migration and invasion of $\mathrm{KI}$.

Notes: ${ }^{* * P}<0.01$. (A) Wound-healing assays demonstrated the migration ability of $\mathrm{KI}$ cells. Representative images at 0 and 24 hours are shown. (B) Transwell assays were performed to determine the migration ability of $\mathrm{KI}$ cells with fibronectin I knockdown. Representative images of migrating cells at a lower chamber stained with crystal violet. (C) Transwell assays were performed to determine the invasion ability of $\mathrm{KI}$ cells with fibronectin I knockdown. Representative images of invasive cells in the lower chamber stained with crystal violet. (D) Quantification of cell migration presented as migrated cell numbers. (E) Quantification of cell invasion presented as invasive cell numbers. All data expressed as means \pm standard deviation of three independent experiments.

Abbreviations: shRNA, short hairpin RNA; Scr-shRNA, scrambled shRNA.

metastasis. ${ }^{21,22}$ EMT is a process involved in embryonic development, during which cells lose their epithelial features and adopt characteristics of mesenchymal cells. EMT also plays a role in cancer invasion and metastasis in a sequence of discrete steps. ${ }^{23,24}$ Decreased expression of the epithelial marker E-cadherin and increased expression of mesenchymal markers, such as N-cadherin and fibronectin, are the most important features of EMT. ${ }^{25}$ E-cadherin has promise as a marker to identify colorectal cancer patients at risk for metastatic disease independently of LN evaluation and imaging results. ${ }^{26}$ In addition, EMT biomarkers can also interact with one another in certain tumors. It has been reported that Snail overexpression causes a decrease in the expression of epithelial markers E-cadherin and $\beta$-catenin and an increase in mesenchymal (Snail and vimentin) marker expression. ${ }^{27}$ Gain of fibronectin alters the component of the extracellular matrix, and the tumor then acquires invasive capacity. ${ }^{28}$ Association between fibronectin expression and invasiveness has been documented in several tumors, such as breast and lung. ${ }^{21,29,30}$ The role of fibronectin in follicular TC has been studied in in vivo experiments. ${ }^{31}$ However, little is known about the biological function of fibronectin 1 in PTC. Our understanding of the role of fibronectin 1 in PTC metastasis remains limited.

According to our study, fibronectin 1 expression was significantly increased in PTC patients with LNM compared to patients without LNM. There were no correlations between the expression level of fibronectin 1 and clinicopathological characteristics, except for tumor size, cervical LN involvement, and pTNM stage. Our study indicated that fibronectin 1 overexpression was associated with larger PTC tumor size, PTC LNM and an advanced pTNM stage, which is reported for the first time. This study also primarily analyzed the diagnostic value of fibronectin 1 in differentiating LNM from non-LNM in PTC. In this cohort of patients, we showed that fibronectin 1 sensitivity was $80 \%$ in identifying overall cervical LNM in PTC, which was much higher than ultrasonography evaluation in previous studies. ${ }^{32,33}$ Fibronectin 1 specificity in predicting PTC LNM was similar compared to ultrasound examination. ${ }^{33,34}$ The study indicated that fibronectin 1 could be a potential diagnostic biomarker for predicting LNM in PTC.

In the past few decades, various mechanisms for cancer metastasis have been investigated. ${ }^{29,35-37}$ However, the mechanism for LNM in PTC has not been comprehensively reported. EMT is a well-known process involved in cancer metastasis..$^{38,39}$ There are functional genes modulating EMT, resulting in tumor progression. ${ }^{32}$ Fibronectin 1 is one of the EMT regulators that was found to be upregulated in aggressive TC. ${ }^{11}$ In our study, the role of fibronectin 1 was investigated in PTC cell lines. Transwell and would-healing assays showed that the migration and invasive ability of PTC cells were both increased by fibronectin 1 overexpression. Likewise, colony-formation assay and CCK-8 analysis demonstrated that PTC-proliferation ability was promoted by fibronectin 1 overexpression. Fibronectin 1 function was 

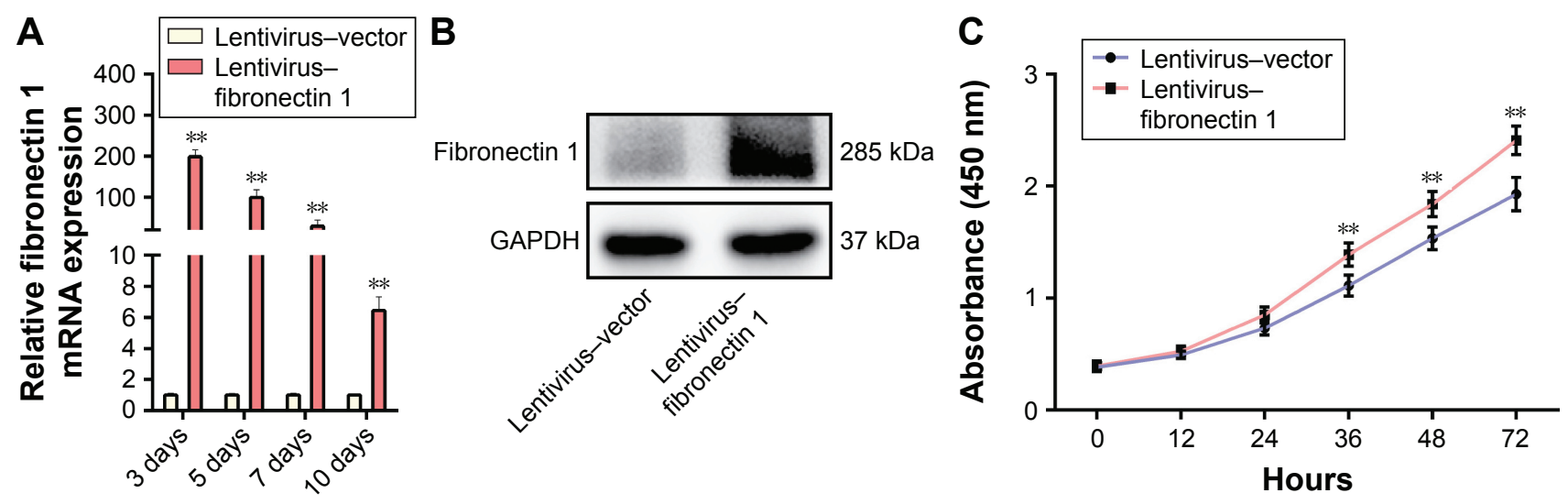

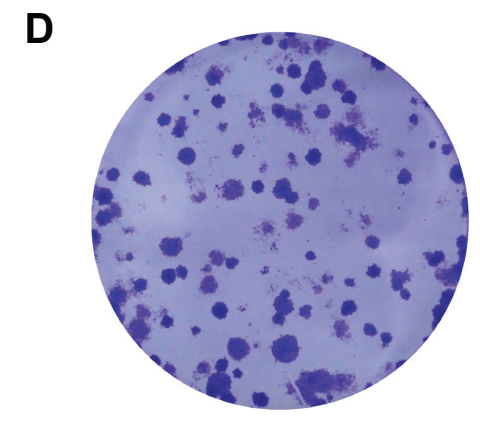

Lentivirus-vector

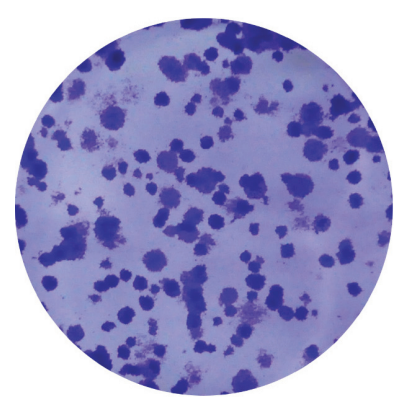

Lentivirus-fibronectin 1
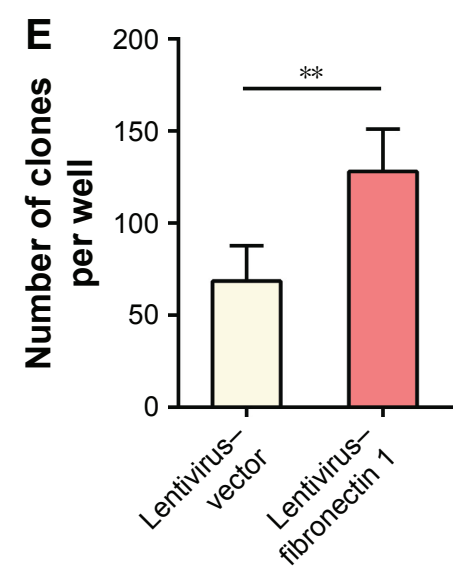
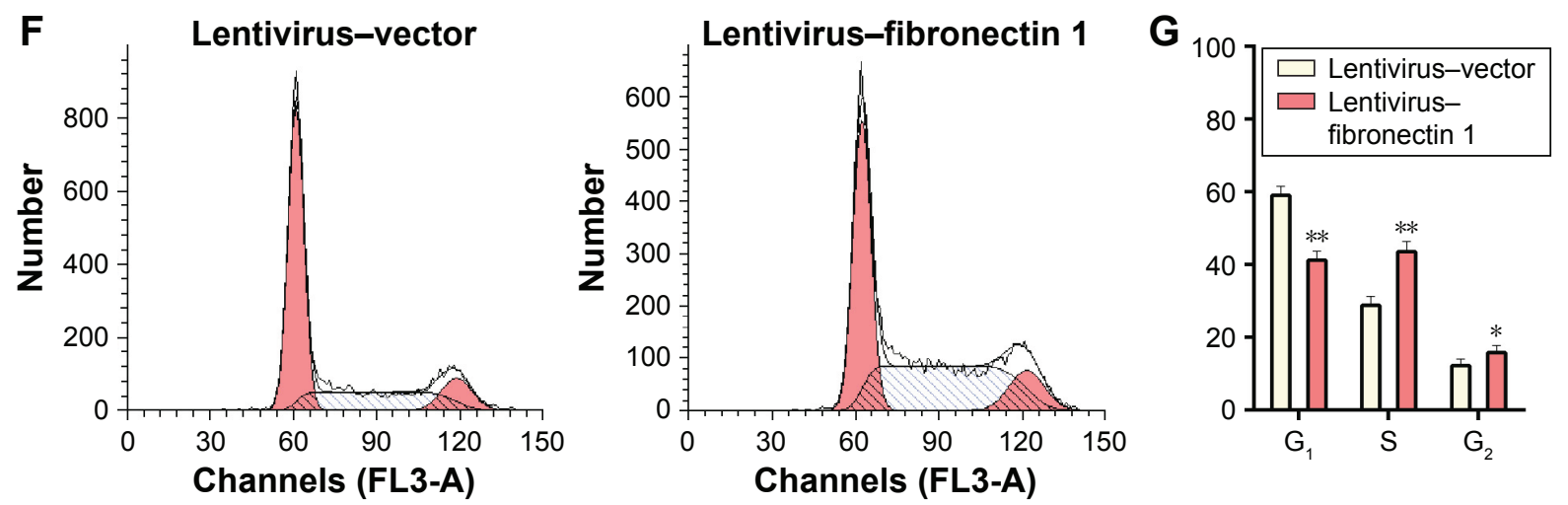

Figure 5 Fibronectin I overexpression promotes TPCI proliferation.

Notes: $* P<0.05, * * P<0.01$. (A) qRT-PCR analysis of mRNA fibronectin I-expression levels in TPCI cells transfected with lentivirus-fibronectin I or lentivirus-vector on days 3, 5, 7, and 10. (B) Western blot analysis of fibronectin I in TPCI cells transfected with fibronectin I plasmid. (C) CCK-8 assays were performed to determine TPCI cell proliferation at $12,24,36,48$, and 72 hours following transfection with fibronectin I plasmid. (D) Colony formation assays were performed to determine the proliferation of TPCI cells transfected with fibronectin I plasmid. (E) Colony-formation assay results. (F) Flow-cytometry images of the cell cycle in TPCI. (G) Results quantified in the cell cycle shown as a percentage of the total cells. All data expressed as means \pm standard deviation of three independent experiments.

Abbreviations: qRT-PCR, quantitative reverse-transcription polymerase chain reaction; mRNA, messenger RNA.

consistent with that reported in other tumors. ${ }^{40-42}$ In vitro data indicated that overexpression of fibronectin 1 promoted PTC metastasis. However, previous in vivo studies of follicular TC have indicated that attenuated fibronectin expression demonstrates a more aggressive growth pattern and more numerous lung metastases in xenografted mice. ${ }^{31,43}$ The possible explanation for the opposite observation in vivo and in vitro could be because they are different pathological subtypes of TC. In vivo functional study of fibronectin 1 in PTC merits further investigation.

\section{Conclusion}

This study demonstrated that fibronectin 1 plays a critical role in TC metastasis by modulating the proliferation, migration, 


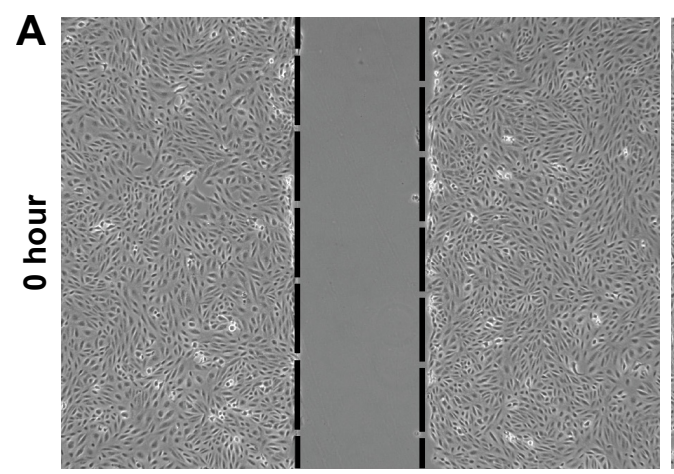

Lentivirus-vector

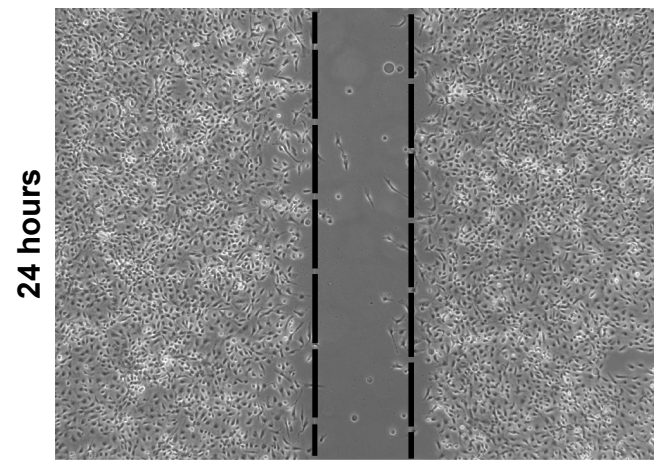

Lentivirus-vector

B

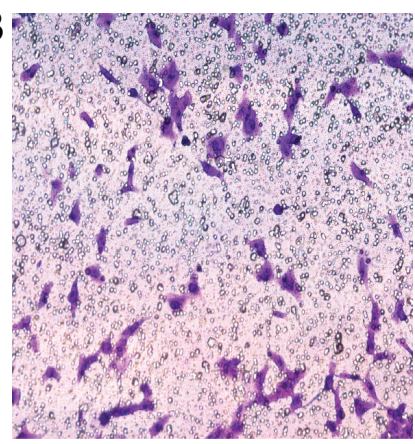

Lentivirus-vector

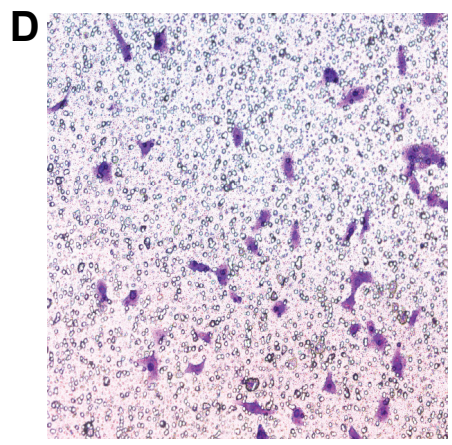

Lentivirus-vector

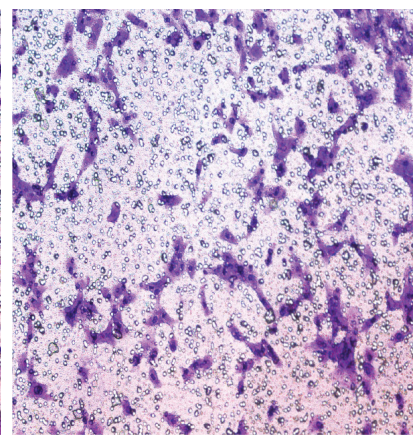

Lentivirus-fibronectin 1

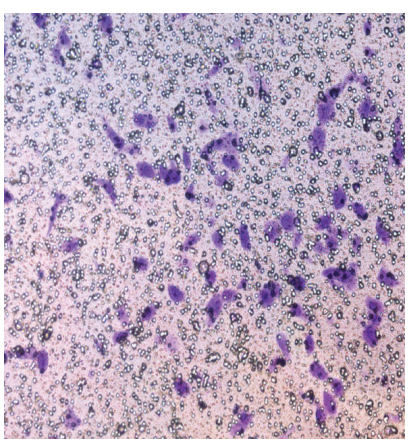

Lentivirus-fibronectin 1

\section{Lentivirus-fibronectin 1}

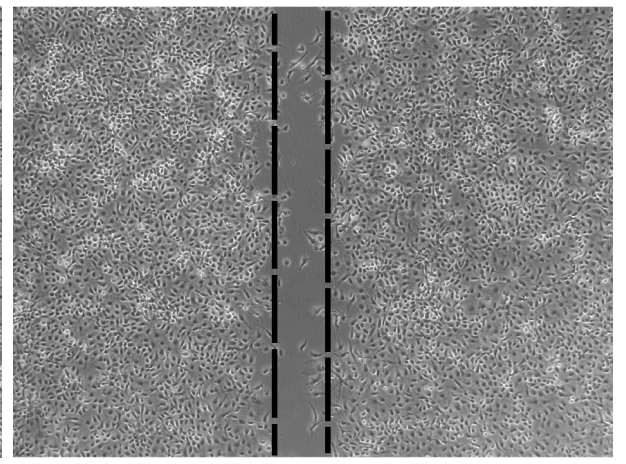

Lentivirus-fibronectin 1
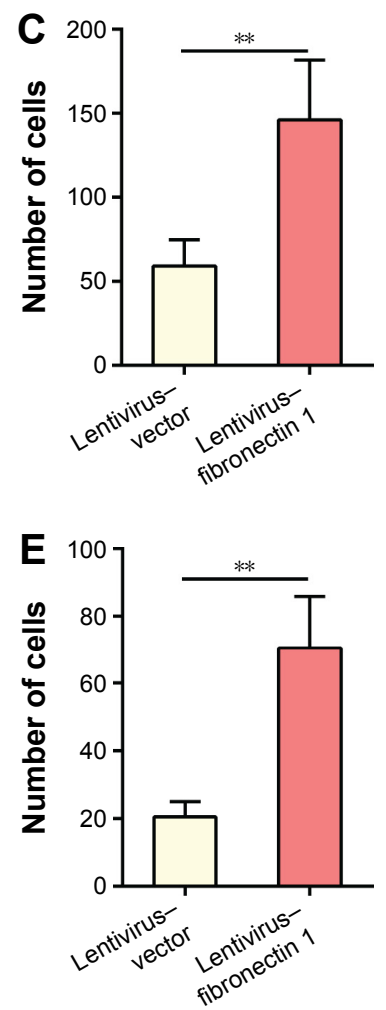

Figure 6 Fibronectin I overexpression promotes the migration and invasion of TPCI.

Notes: ${ }^{*} \mathrm{P}<0.0 \mathrm{I}$. (A) Wound-healing assays were performed to determine the migration ability of TPCI cells. Representative images at 0 and 24 hours are shown. (B) Transwell assays were performed to determine the migration ability of TPCI cells with fibronectin I overexpression. Representative images of migrating cells in the lower chamber stained with crystal violet. (C) Transwell assays were performed to determine the invasion ability of TPCI cells with fibronectin I overexpression. Representative images of invasive cells in the lower chamber stained with crystal violet. (D) Quantification of cell migration presented as migrated cell numbers. (E) Quantification of cell invasion presented as invasive cell numbers. All data expressed as means \pm standard deviation of three independent experiments. 
and invasion ability of PTC cells. Fibronectin 1 is associated with PTC LNM, and is a valuable diagnostic biomarker for predicting LNM in PTC.

\section{Acknowledgments}

The work was supported by the National Natural Science Foundation of China (81471668 and 81671688). The funding agency had no role in study design, data collection, analysis, decision to publish, or preparation of the manuscript.

\section{Disclosure}

The authors report no conflicts of interest in this work.

\section{References}

1. Hundahl SA, Fleming ID, Fremgen AM, Menck HR. A National Cancer Data Base report on 53,856 cases of thyroid carcinoma treated in the U.S., 1985-1995. Cancer. 1998;83(12):2638-2648.

2. Lundgren CI, Hall P, Dickman PW, Zedenius J. Clinically significant prognostic factors for differentiated thyroid carcinoma: a populationbased, nested case-control study. Cancer. 2006;106(3):524-531.

3. Zaydfudim V, Feurer ID, Griffin MR, Phay JE. The impact of lymph node involvement on survival in patients with papillary and follicular thyroid carcinoma. Surgery. 2008;144(6):1070-1078.

4. Shindo M, Wu JC, Park EE, Tanzella F. The importance of central compartment elective lymph node excision in the staging and treatment of papillary thyroid cancer. Arch Otolaryngol Head Neck Surg. 2006;132(6):650-654.

5. Caron NR, Clark OH. Papillary thyroid cancer: surgical management of lymph node metastases. Curr Treat Options Oncol. 2005;6(4): 311-322.

6. Patron V, Hitier M, Bedfert C, Le Clech G, Jégoux F. Occult lymph node metastases increase locoregional recurrence in differentiated thyroid carcinoma. Ann Otol Rhinol Laryngol. 2012;121(5): 283-290.

7. Leboulleux S, Rubino C, Baudin E, et al. Prognostic factors for persistent or recurrent disease of papillary thyroid carcinoma with neck lymph node metastases and/or tumor extension beyond the thyroid capsule at initial diagnosis. J Clin Endocrinol Metab. 2005;90(10): 5723-5729.

8. Ito Y, Tomoda C, Uruno T, et al. Clinical significance of metastasis to the central compartment from papillary microcarcinoma of the thyroid. World J Surg. 2006;30(1):91-99.

9. Ito Y, Tomoda C, Uruno T, et al. Ultrasonographically and anatomopathologically detectable node metastases in the lateral compartment as indicators of worse relapse-free survival in patients with papillary thyroid carcinoma. World J Surg. 2005;29(7):917-920.

10. Moon PG, Lee JE, Cho YE, et al. Fibronectin on circulating extracellular vesicles as a liquid biopsy to detect breast cancer. Oncotarget. 2016; 7(26):40189-40199.

11. Sponziello M, Rosignolo F, Celano M, et al. Fibronectin-1 expression is increased in aggressive thyroid cancer and favors the migration and invasion of cancer cells. Mol Cell Endocrinol. 2016;431:123-132.

12. Takeyama H, Kyoda S, Okamoto $\mathrm{T}$, et al. The expression of sialic fibronectin correlates with lymph node metastasis of thyroid malignant neoplasmas. Anticancer Res. 2011;31(4):1395-1398.

13. Vendittelli F, Raffaelli M, Fadda G, et al. Blood presence of circulating oncofetal fibronectin mRNA, by RT-PCR, does not represent a useful specific marker for the management and follow-up of thyroid cancer patients. Clin Chem Lab Med. 2012;50(4):715-720.

14. Saiselet M, Floor S, Tarabichi M, et al. Thyroid cancer cell lines: an overview. Front Endocrinol (Lausanne). 2012;3:133.
15. Haugen BR, Alexander EK, Bible KC, et al. 2015 American Thyroid Association management guidelines for adult patients with thyroid nodules and differentiated thyroid cancer. Thyroid. 2016;26(1):1-133.

16. Esnaola NF, Cantor SB, Sherman SI, Lee JE, Evans DB. Optimal treatment strategy in patients with papillary thyroid cancer: a decision analysis. Surgery. 2001;130(6):921-930.

17. de AlmeidaPG,PinheiroGG, Nunes AM, Gonçalves AB, ThorsteinsdóttirS. Fibronectin assembly during early embryo development: a versatile communication system between cells and tissues. Dev Dyn. 2016; 245(4):520-535.

18. Maione AG, Smith A, Kashpur O, et al. Altered ECM deposition by diabetic foot ulcer-derived fibroblasts implicates fibronectin in chronic wound repair. Wound Repair Regen. 2016;24(4):630-643.

19. Wang Y, Ni H. Fibronectin maintains the balance between hemostasis and thrombosis. Cell Mol Life Sci. 2016;73(17):3265-3277.

20. Nishioka T, Arima N, Kano K, et al. ATX-LPA1 axis contributes to proliferation of chondrocytes by regulating fibronectin assembly leading to proper cartilage formation. Sci Rep. 2016;6:23433.

21. Jeon M, Lee J, Nam SJ, Shin I, Lee JE, Kim S. Induction of fibronectin by HER 2 overexpression triggers adhesion and invasion of breast cancer cells. Exp Cell Res. 2015;333(1):116-126.

22. Morita Y, Hata K, Nakanishi M, et al. Cellular fibronectin 1 promotes VEGF-C expression, lymphangiogenesis and lymph node metastasis associated with human oral squamous cell carcinoma. Clin Exp Metastasis. 2015;32(7):739-753.

23. Hanahan D, Weinberg RA. Hallmarks of cancer: the next generation. Cell. 2011;144(5):646-674.

24. Thiery JP. Epithelial-mesenchymal transitions in tumour progression. Nat Rev Cancer. 2002;2(6):442-454.

25. Sun L, Fang J. Epigenetic regulation of epithelial-mesenchymal transition. Cell Mol Life Sci. 2016;73(23):4493-4515.

26. Busch EL, Keku TO, Richardson DB, et al. Evaluating markers of epithelial-mesenchymal transition to identify cancer patients at risk for metastatic disease. Clin Exp Metastasis. 2016;33(1):53-62.

27. Yang YJ, Li ZB, Zhang GR, et al. Snail-induced epithelial-mesenchymal transition in gastric carcinoma cells and generation of cancer stem cell characteristics. Genet Mol Res. 2016;15(3):15038510.

28. Kalluri R, Weinberg RA. The basics of epithelial-mesenchymal transition. J Clin Invest. 2009;119(6):1420-1428.

29. Yousif NG. Fibronectin promotes migration and invasion of ovarian cancer cells through up-regulation of FAK-PI3K/Akt pathway. Cell Biol Int. 2014;38(1):85-91.

30. Pal S, Ganguly KK, Chatterjee A. Extracellular matrix protein fibronectin induces matrix metalloproteinases in human prostate adenocarcinoma cells PC-3. Cell Commun Adhes. 2013;20(5):105-114.

31. Liu W, Asa SL, Ezzat S. 1 $\alpha, 25$-Dihydroxyvitamin D3 targets PTENdependent fibronectin expression to restore thyroid cancer cell adhesiveness. Mol Endocrinol. 2005;19(9):2349-2357.

32. Leboulleux S, Girard E, Rose M, et al. Ultrasound criteria of malignancy for cervical lymph nodes in patients followed up for differentiated thyroid cancer. J Clin Endocrinol Metab. 2007;92(9):3590-3594.

33. Hwang HS, Orloff LA. Efficacy of preoperative neck ultrasound in the detection of cervical lymph node metastasis from thyroid cancer. Laryngoscope. 2011;121(3):487-491.

34. Kim E, Park JS, Son KR, Kim JH, Jeon SJ, Na DG. Preoperative diagnosis of cervical metastatic lymph nodes in papillary thyroid carcinoma: comparison of ultrasound, computed tomography, and combined ultrasound with computed tomography. Thyroid. 2008;18(4): 411-418.

35. Rankin EB, Giaccia AJ. Hypoxic control of metastasis. Science. 2016; 352(6282):175-180.

36. Massague J, Obenauf AC. Metastatic colonization by circulating tumour cells. Nature. 2016;529(7586):298-306.

37. Syn N, Wang L, Sethi G, Thiery JP, Goh BC. Exosome-mediated metastasis: from epithelial-mesenchymal transition to escape from immunosurveillance. Trends Pharmacol Sci. 2016;37(7): 606-617. 
38. Imani S, Hosseinifard H, Cheng J, Wei C, Fu J. Prognostic value of EMTinducing transcription factors (EMT-TFs) in metastatic breast cancer: a systematic review and meta-analysis. Sci Rep. 2016;6:28587.

39. $\mathrm{Wu} \mathrm{C}$, Zhuang $\mathrm{Y}$, Jiang $\mathrm{S}$, et al. Interaction between $\mathrm{Wnt} / \beta$-catenin pathway and microRNAs regulates epithelial-mesenchymal transition in gastric cancer (review). Int J Oncol. 2016;48(6):2236-2246.

40. Kenny HA, Chiang CY, White EA, et al. Mesothelial cells promote early ovarian cancer metastasis through fibronectin secretion. J Clin Invest. 2014;124(10):4614-4628.

41. Li W, Liu Z, Zhao C, Zhai L. Binding of MMP-9-degraded fibronectin to $\beta 6$ integrin promotes invasion via the FAK-Src-related Erk1/2 and PI3K/ Akt/Smad-1/5/8 pathways in breast cancer. Oncol Rep. 2015;34(3): 1345-1352.
42. Han S, Khuri FR, Roman J. Fibronectin stimulates non-small cell lung carcinoma cell growth through activation of Akt/mammalian target of rapamycin/S6 kinase and inactivation of LKB1/AMP-activated protein kinase signal pathways. Cancer Res. 2006;66(1):315-323.

43. Liu W, Cheng S, Asa SL, Ezzat S. The melanoma-associated antigen A3 mediates fibronectin-controlled cancer progression and metastasis. Cancer Res. 2008;68(19):8104-8112.

\section{Publish your work in this journal}

OncoTargets and Therapy is an international, peer-reviewed, open access journal focusing on the pathological basis of all cancers, potential targets for therapy and treatment protocols employed to improve the management of cancer patients. The journal also focuses on the impact of management programs and new therapeutic agents and protocols on

\section{Dovepress}

patient perspectives such as quality of life, adherence and satisfaction The manuscript management system is completely online and includes a very quick and fair peer-review system, which is all easy to use. Visit http://www.dovepress.com/testimonials.php to read real quotes from published authors.

Submit your manuscript here: http://www.dovepress.com/oncotargets-and-therapy-journal 